\title{
HOSPITAL SOUNDSCAPE: ACOUSTICS EVALUATION IN NEONATAL INTENSIVE CARE UNIT (NICU) ROOM OF A NATIONAL HOSPITAL IN JAKARTA, INDONESIA
}

\author{
SARWONO, R. Sugeng Joko ${ }^{1 *}$, WULANDHARI, Rezzy Yolanda ${ }^{2}$, HABIBA, Sofiya ${ }^{3}$, AZZAHRA, Iva \\ Rofiatun Nisa ${ }^{4}$, UTAMI, Sentagi Sesotya ${ }^{5}$, HARDJOPRAWITO, Tri Juda Airlangga ${ }^{6}$, \\ SEDONO, Rudyanto ${ }^{7}$ \\ ${ }^{1,2,3,4}$ Engineering Physics Department, Institut Teknologi Bandung, Indonesia \\ ${ }^{5}$ Engineering Physics Department, Universitas Gadjah Mada, Indonesia \\ 6,7 RSUPN Dr.Cipto Mangunkusumo, Indonesia \\ *Corresponding author: jsarwono@tt.itb.ac.id
}

\begin{abstract}
Acoustics comfort in a room is one of the most important building physics aspect that should be observed. in public spaces like hospital, especially in an intensive care unit such as NICU. Researches on the acoustic conditions of NICU in Indonesia are still limited. The acoustical study conducted in this research is using objective, subjective, and simulation methods based on soundscape concept with the concern on the nurse's perception. This research was conducted at a national hospital in Jakarta. According to National Standardization Agency of Indonesia (SNI) and World Health Organization (WHO), the suitable sound pressure level (SPL) for noise in patient's room is $35 \mathrm{dBA}$. From the study, it was found that the equivalent SPL value exceeded the standard. Soundscape in NICU can be improve with the addition of curtain on the incubator's side, installation of glass partition, and ceiling absorber in the nurse station area. The result of simulation showed that the SPL in the room decreased with average value $8.9 \mathrm{dBA}$ for sound source alarm ventilator and $8.2 \mathrm{dBA}$ for sound source medical officer conversations. And the speech transmission index (STI) increased from "bad" to "good" range became "fair" to "excellent" range.
\end{abstract}

Keywords: Acoustic; soundscape; neonatal intensive care unit.

\section{INTRODUCTION}

Hospital as one of the public facilities must pay attention carefully on its building physics aspects. According to Ryherd et al., (2007), the acoustic arrangements are important since the hospital acoustics condition should be conducive. It can affect the health of the patients and productivity of the staffs. Based on the research of Ryherd et al. in one of the hospital in Sweden, 91\% nurses agreed that noise can create negative impact for the nurses, and $96 \%$ of them agreed that noise can also give impact for patient's health.

The room in the hospital observed in this study is the NICU. NICU is a special intensive care unit for newborns up to 28 days old baby who requires treatment and special care to prevent and treat the occurrence of the failure of vital organs (retrieved from http://bunda.co.id/rsiabundajakarta/id_ID /facilities-and-services/support-facilities/nicupicu/). Based on research by Sieben et al., (2009), some factors influenced the acoustics condition in NICU, i.e. outdoor environment, building equipment like exhaust fans, working sounds like sanitizer dispenser, medical equipment, and also medical staff conversation in the room.

Nowadays, the sound pressure level (SPL) is no longer the only benchmark in determining the acoustics quality of a room. Over time, the concept of soundscape, which states that the acoustics quality can also be determined by the human perception, continues to grow. ISO define soundscape as acoustic condition, which focused on how those acoustic conditions are perceived or understood by a person or groups of people. R. Murray Schafer developed this concept in 1970's. Three methods are used to determine the soundscape condition in this research, i.e. objective assessment, subjective assessment, and simulation using CATT-Acoustic v9.0. Measurement tools for the objective assessment were Rion NA-28 and Zoom H6 Handy Recorder. The subjective assessment was done by distributing questionnaire to 21 nurses as the respondents.

Soundscape related research that focuses on NICU are still limited in Indonesia. Especially research that focus on the nurses as the subject. For that reason, and because it is not possible to evaluate the acoustics condition perceived by the infants, 
nurses have been selected as the respondent of this research.

\section{METHODS}

Objective measurement is used to collect existing soundscape conditions of the NICU and several parameters observed are used as data input for the simulation using CATT-Acoustic v9.0, as an attempt to find out improvement of the existing condition. This includes the geometry data of the room or space. The result obtained from the objective measurement are supported by the occupant's audial perception through subjective evaluation based on survey using questionnaire.

\section{Objective Assessment}

Instruments used in the objective measurement are Rion NA-28 and H6 Zoom Handy Recorder with MSH-6 Microphone. The value of sound pressure level (SPL) at each octave band frequency in every second were measure using Rion NA-28. The data that obtained were process in order to get the value of equivalent sound pressure level $\left(\mathrm{L}_{\text {Aeq }}\right)$ and the percentile level used $\left(\mathrm{L}_{10}, \mathrm{~L}_{50}\right.$, and $\left.\mathrm{L}_{90}\right)$. The second measuring instrument used is H6 Zoom Handy Recorder.

Five measurement points were use as shown in Figure 1. The acoustic data of each points were taken every 3 minutes for 24 hours. The measurement points were determined based on the ISO 3382-3: 2012 and the noise source position in the room with some adjusments, considering the existing condition of the NICU. Measurement points located 2 meters from the walls and 0.5 meters from the table. The NICU was adjacent to a main corridor. Glass and wall were used as the boundaries.

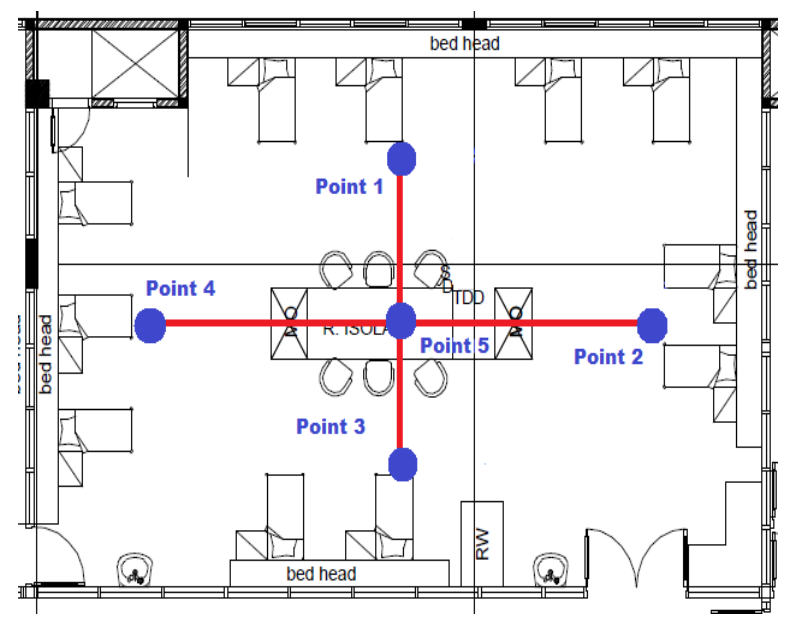

Fig. 1. Measurement Points in Neonatal Intensive Care Unit

\section{Subjective Assessment}

Subjective assessment was carried out by distributing questionnaire to the nurses and recording the noise sources inside the room. The result of the recorded sounds were used to determine the noise source and its range of frequency. Questionnaires divided into two kinds of forms. The first one was fill in form questionnaire, where the respondentswrote their opinion about the existing condition of the room. Second, rating scale form, where the respondents were asked to rate the acoustics condition based on the statement in the questionnaire. There were 21 respondents, divided into three shifts (morning shift, noon shift, and night shift). Every 3 months, the shift are rotated, so in this research, the nurse's shift for the questionnaire are less concerned since every nurse worked in morning, noon, and night shifts.

\section{Simulation}

Simulation was carried out by using CATTAcoustic v9.0 with ray-tracing method. The geometrical model of the room was made using SketchUp 2016, based on the actual size and geometry of the NICU. The model was then treated by modifying the absorption coefficient of the surfaces of the objects inside the room using data from Vorlander (2007), http://www.sengpielaudio. com, and www.acoustic.ua as the main references. The absorption coefficient used have values for frequency range of $125 \mathrm{~Hz}, 250 \mathrm{~Hz}, 500 \mathrm{~Hz}, 1000$ $\mathrm{Hz}, 2000 \mathrm{~Hz}$, and $4000 \mathrm{~Hz}$. The absorption coefficients can be seen in Table 1 and the absorption coefficients for the object of the improved design can be seen in table 2 .

\section{RESULTS}

\section{Objective Assessment Results}

The parameters used in objective assessment are $\mathrm{L}_{\text {Aeq }}, \mathrm{L}_{10}, \mathrm{~L}_{50}$, and $\mathrm{L}_{90}$. Figure 2 shows the equivalent sound pressure level and percentile level in Neonatal Intensive Care Unit for 1 x 24 hours.

From Figure 2, it can be seen that the highest $\mathrm{L}_{\text {Aeq }}$ occured from $08.00-12.00$ with sound pressure level varied between $61.2 \mathrm{dBA}$ and $61.7 \mathrm{dBA}$. Based on National Standardization Agency of Indonesia (SNI), sound pressure level allowed in patient room with two or more beds is $35 \mathrm{dBA}$ and maximum sound pressure level allowed is $40 \mathrm{dBA}$. Furthermore, World Health Organization states that equivalent sound pressure level allowed in patient room should not exceed $35 \mathrm{dBA}$. It means the sound pressure level in the NICU exceeded the standards. 
Table 1. Absorption Coefficient

\begin{tabular}{llllllll}
\hline \multirow{2}{*}{ Object } & \multicolumn{1}{c}{ Material } & \multicolumn{5}{c}{ Frequency $(\mathrm{Hz})$} \\
\cline { 3 - 8 } & & $\mathbf{1 2 5}$ & $\mathbf{2 5 0}$ & $\mathbf{5 0 0}$ & $\mathbf{1 0 0 0}$ & $\mathbf{2 0 0 0}$ & $\mathbf{4 0 0 0}$ \\
\hline Wall & Brick & 0.02 & 0.02 & 0.03 & 0.03 & 0.04 & 0.05 \\
Window & Glass, 5 mm thickness & 0.35 & 0.25 & 0.18 & 0.12 & 0.07 & 0.04 \\
Ceiling & Sheet-rock 1/2" 16" on centeryyyyyyyyyyyyy & 0.29 & 0.1 & 0.05 & 0.04 & 0.07 & 0.09 \\
Incubator & Acrilic & 0.08 & 0.04 & 0.03 & 0.03 & 0.02 & 0.02 \\
& Alumuni-um & 0.02 & 0.02 & 0.03 & 0.035 & 0.038 & 0.038 \\
Floor & Linoleum & 0.02 & 0.02 & 0.03 & 0.04 & 0.04 & 0.05 \\
Sink & Ceramic & 0.01 & 0.01 & 0.01 & 0.02 & 0.02 & 0.02 \\
Chair & Fabric uphol-stered & 0.6 & 0.74 & 0.88 & 0.96 & 0.93 & 0.85 \\
Table & Plywood, hardwood panels & 0.3 & 0.2 & 0.15 & 0.1 & 0.1 & 0.05 \\
Bed head & 12 mm plywood & 0.25 & 0.05 & 0.04 & 0.03 & 0.03 & 0.02 \\
Cupboard & Chipboard & 0.12 & 0.04 & 0.06 & 0.05 & 0.05 & 0.05 \\
Trash can & Plastic & 0.07 & 0 & 0.14 & 0 & 0.14 & 0.14 \\
Door & Solid wooden door & 0.14 & 0.1 & 0.06 & 0.08 & 0.1 & 0.1 \\
\hline
\end{tabular}

Table 2. Absorption Coefficient for Improved Design

\begin{tabular}{|c|c|c|c|c|c|c|}
\hline \multirow{2}{*}{ Material } & \multicolumn{6}{|c|}{ Frequency $(\mathrm{Hz})$} \\
\hline & 125 & 250 & 500 & 1000 & 2000 & 4000 \\
\hline Curtain fabric, folded & 0.12 & 0.60 & 0.98 & 0.99 & 0.99 & 0.99 \\
\hline $\begin{array}{l}\text { Acoustic ceiling (Fibre absorber on perforated } \\
\text { sheet metal cartridge, } 0,5 \mathrm{~mm} \text { zinc-plated steel, } \\
\text { diameter } 1,5 \mathrm{~mm} \text { ) }\end{array}$ & 0.48 & 0.97 & 0.99 & 0.97 & 0.99 & 0.99 \\
\hline Glass & 0.30 & 0.20 & 0.10 & 0.07 & 0.05 & 0.02 \\
\hline
\end{tabular}

In this measurement, event log recording also used to identify sound source showed by Figure 3 . The color gradation indicates the occurence frequency of sound source. The darker color in Figure 3 showed that the sound source were heard more often. It was used to determine which sound source act as the main noise source for the nurses who worked in this room.

From Figure 3, we can see that noise sources in NICU are alarm ventilator in a dominant frequency range of $250 \mathrm{~Hz}-4 \mathrm{kHz}$, saturation monitor at 250 $\mathrm{Hz}-4 \mathrm{kHz}$, incubator at $250 \mathrm{~Hz}-4 \mathrm{kHz}$., syringe pump and infus pump in the frequency range of 4 $\mathrm{kHz}-8 \mathrm{kHz}$, and the conversation from the nurse and doctor in the room. From measurements, it can be concluded that sound pressure level in NICU did not meet the standards of room acoustics.

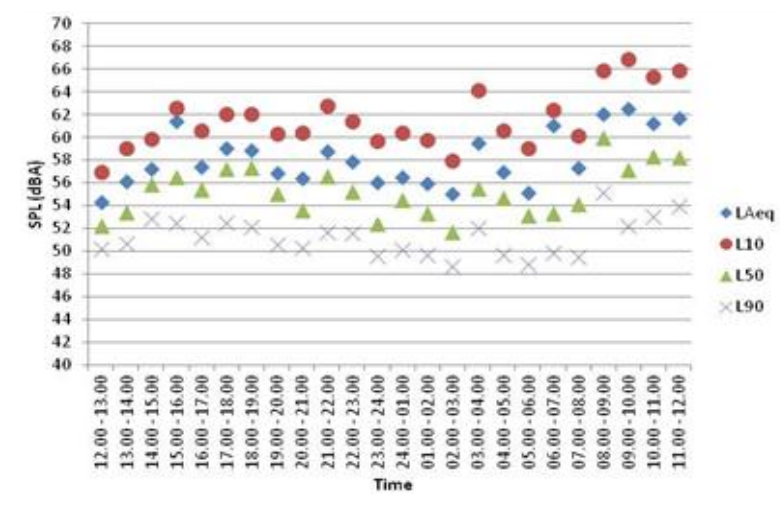

Fig. 2. Equivalent Sound Pressure Level and Percentile Level in NICU

\section{Subjective Assessment Results}

The subjective evaluation is carried out using questionnaire that answered by the nurses who worked in the NICU. In this measurement, we asked about the disturbing sound when the nurses worked, the important sounds in NICU, and the impact between the noise and nurse's performance when they worked. The respondents of this research have been working for between 2 to 25 years, with average working experience was 8 years. Figure 4, Figure 5, and Figure 6 show the results of the subjective assessment. In this interview we also asked scale performance of the acoustics condition in the room to the respondents. The result can be seen in Figure 7.

From Figure 4 and Figure 5 it can be concluded that 2 most unwanted sounds in NICU was all of medical alarms and medical officer conversation. For this research, the important sounds also need to be noted because we can not eliminate the important sounds completely, for example the medical instrumentation alarms that shows the infants condition. Based on Figure 5, the 2 most important sounds was all of medical instruments alarms and saturation monitor. This result shows that if we want to reduce the overall sound pressure level, the SPL value of the important sounds must not fall below the background noise, so the medical officer still can hear the important sounds. 


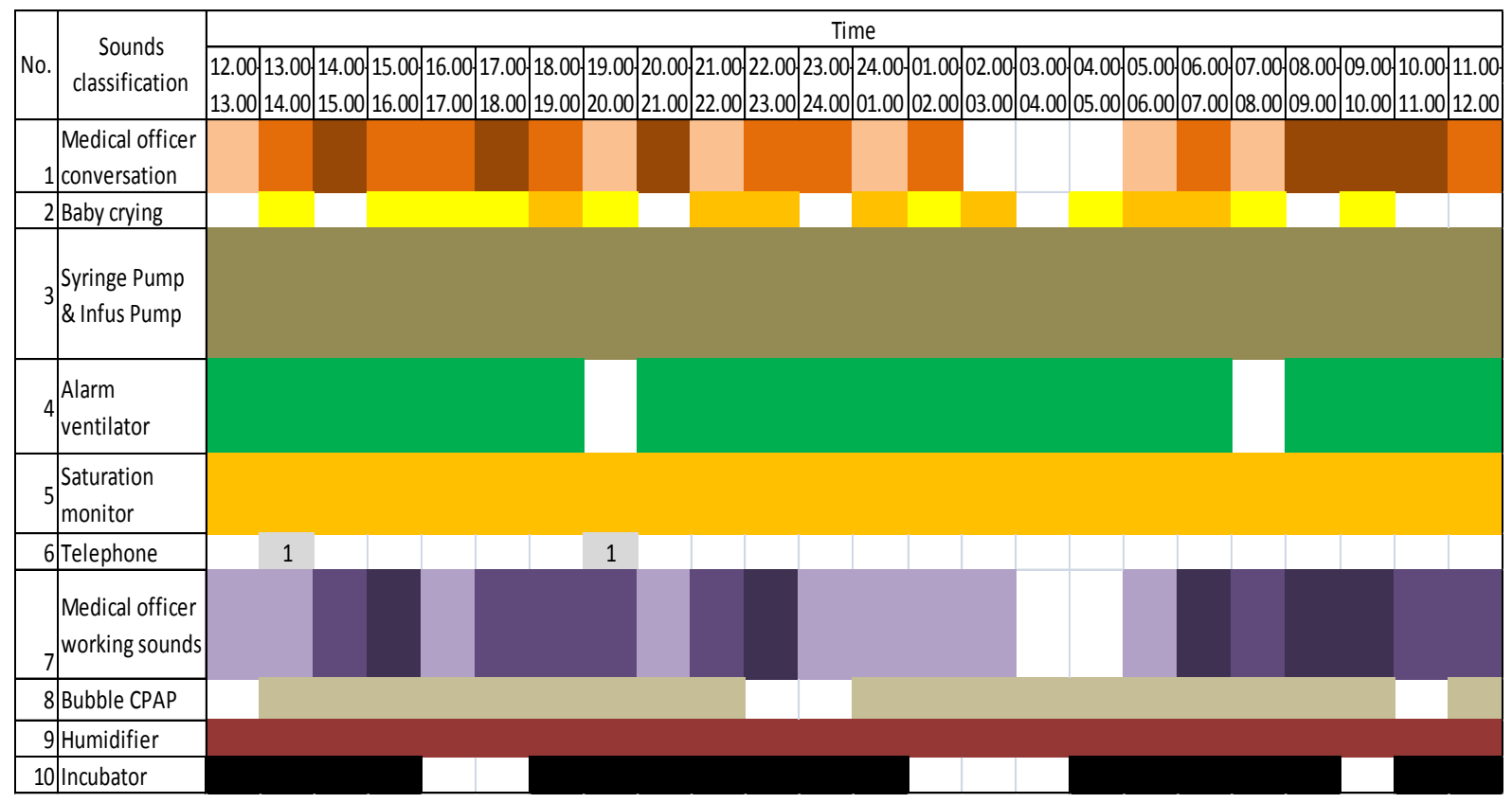

Fig. 3. Sound Mapping in NICU during Measurement

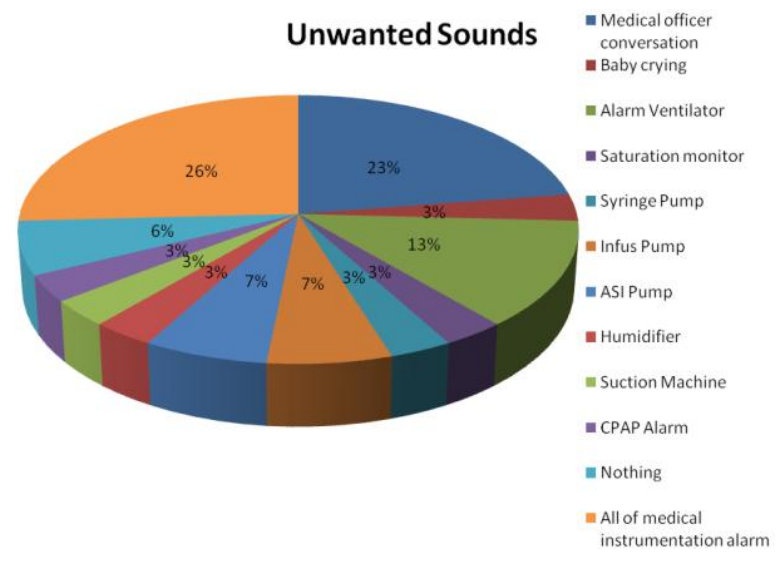

Fig. 4. Unwanted Sounds in NICU

Important Sounds

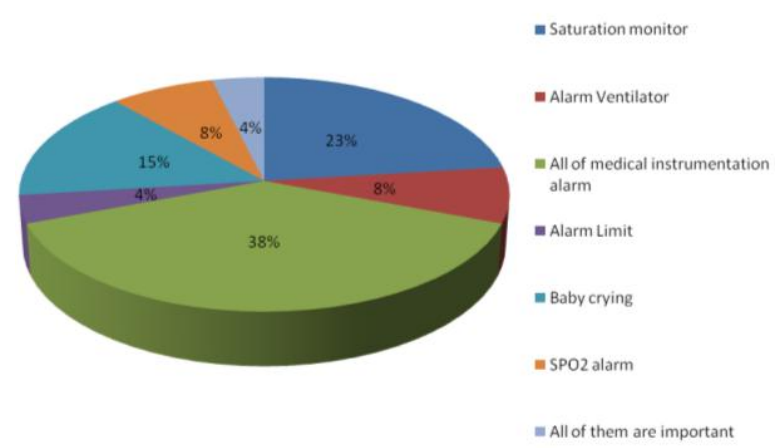

Fig. 5. Important Sounds in NICU

Based on Figure 6, the sounds in NICU gave effect to the nurse's performances. $41 \%$ respondents did not answer this question. It shows that they did not feel the relation between sound in NICU and their performance as nurse. There are $36 \%$ of the respondents agreed noise can distract their works. Among them, $23 \%$ said that they were already accustomed to the situation. It can be affected by their working experiences and their ability to adapt with the condition in NICU.

The acoustics condition of NICU is also determined using a room acoustics scale performances. From calculation, noise in NICU according to the respondents have value of 4.2 scale, where 0.0 indicate a noisy room and 10.0 indicates a quiet room. As for the average acoustic comfort value, according to the respondents is 5.2 , where 0.0 indicates an uncomfortable room and 10.0 indicates a comfortable room. It means that the acoustic condition in NICU still considered as uncomfortable and noisy for the occupants.



Fig. 6. Sound Effects in NICU to Nurse's Performances 


\section{Simulation of Initial Conditions}

Between the real conditions and the simulation there was an error of $2.95 \mathrm{~dB}$. The value of sound pressure level and speech transmission index for each points shown by Table Table 3, Table 4, Table 5, and Table 6. The speech transmission index have value ranged from "bad" to "good". It did not meet the speech transmission index standard for patient room. Based on ISO 9921:2003, the speech transmission index in bed area, parents area, and nurse station must have value ranged "good" to "excellent". Figure 7 shows simulation results of the initial condition using CATT-Acoustic v9.0.

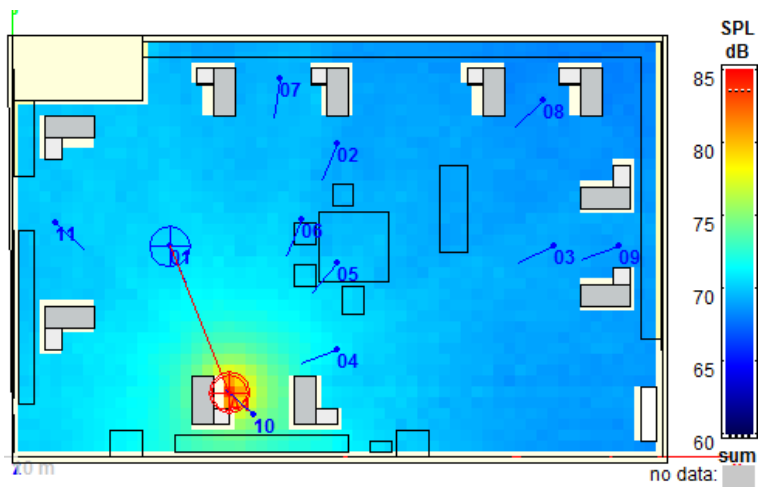

Fig. 7. Sound Pressure Level Initial Conditions with Sound Source Alarm Ventilator

Table 3. Sound Pressure Level Each Points with Sound Source Alarm Ventilator

\begin{tabular}{|c|c|c|c|c|c|}
\hline & $\begin{array}{c}\mathbf{S P L}(\mathrm{A}), \\
\text { dBA }\end{array}$ & & $\begin{array}{c}\mathbf{S P L}(\mathrm{A}), \\
\mathrm{dBA}\end{array}$ & & $\begin{array}{c}\mathbf{S P L}(\mathrm{A}), \\
\text { dBA }\end{array}$ \\
\hline Point 6 & 68.8 & Point 8 & 67.5 & Point 10 & 73.9 \\
\hline Point 7 & 68.2 & Point 9 & 67.9 & Point 11 & 68.8 \\
\hline
\end{tabular}

Table 4. Speech Transmission Index Each Points with Sound Source Alarm Ventilator

\begin{tabular}{llllll}
\hline & STI & & STI & & STI \\
\hline Point 6 & 0.56 & Point 8 & 0.54 & Point 10 & 0.73 \\
Point 7 & 0.54 & Point 9 & 0.54 & Point 11 & 0.55 \\
\hline
\end{tabular}

Table 5. Sound Pressure Level Each Points with Sound Source Medical Officer Conversation

\begin{tabular}{|c|c|c|c|c|c|}
\hline & $\begin{array}{c}\text { SPL(A), } \\
\text { dBA }\end{array}$ & & $\begin{array}{c}\text { SPL(A), } \\
\text { dBA }\end{array}$ & & $\begin{array}{c}\text { SPL(A), } \\
\text { dBA }\end{array}$ \\
\hline $\begin{array}{l}\text { Point } 6 \\
\end{array}$ & 64.3 & $\begin{array}{l}\text { Point } 8 \\
\end{array}$ & 61.6 & Point 10 & 61.0 \\
\hline Point 7 & 61.8 & Point 9 & 61.3 & Point 11 & 61.0 \\
\hline
\end{tabular}

Table 6. Speech Transmission Index Each Points with Sound Source Medical Officer Conversation

\begin{tabular}{llllll}
\hline & STI & & STI & & STI \\
\hline Point 6 & 0.67 & Point 8 & 0.54 & Point 10 & 0.52 \\
Point 7 & 0.56 & Point 9 & 0.53 & Point 11 & 0.52 \\
\hline
\end{tabular}

\section{Simulation of Improved Model}

The improvement solutions using simulation were done by adding some objects, i.e. adding curtain absorber alongside the incubator, using ceiling absorber in nurse station, and glass partitions between the babies area and nurse station. Addition of those objects resulting in reduction of sound pressure level and enhancement of speech transmission index. The value of sound pressure level and speech transmission index of the improved model is shown by Figure 8, Figure 9, Figure 10, and Figure 11.



Fig. 8. Sound Pressure Level after Improvement with Sound Source Alarm Ventilator

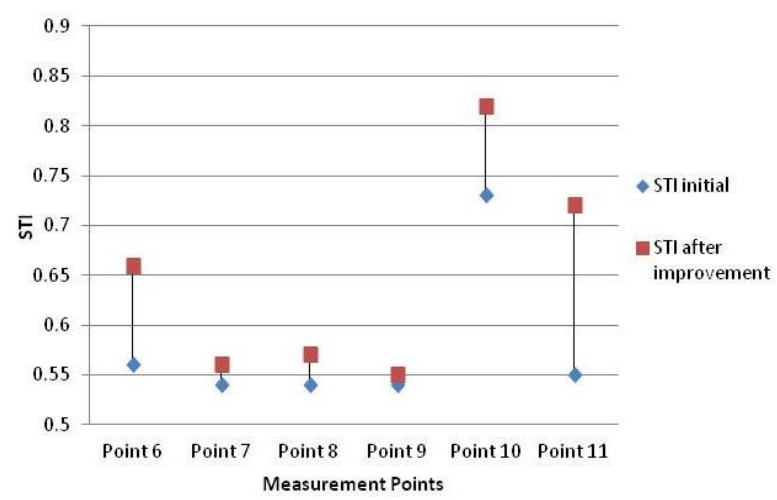

Fig. 9. Speech Transmission Index after Improvement with Sound Source Alarm Ventilator



Fig. 10. Sound Pressure Level after Improvement with Sound Source Medical Officer Conversation 


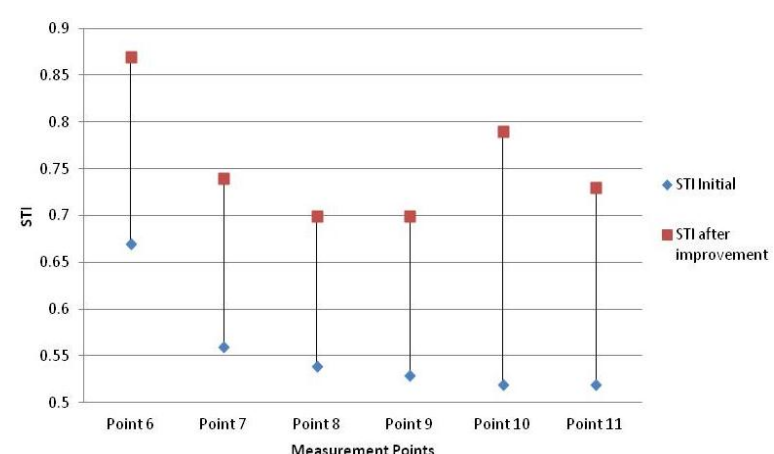

Fig. 11. Speech Transmission Index after Improvement with Sound Source Medical Officer Conversation

From Figure 7, Figure 8, Figure 9, and Figure 10 it can be concluded that the addition of curtain absorber alongside the incubator, using ceiling absorber in nurse station, and glass partitions between the babies area and nurse station were able to decrease the sound pressure level with an average of $8.9 \mathrm{dBA}$ for sound source alarm ventilator, and 8.2 dBA for sound source medical officer conversation. The speech transmission index increased from "bad" to "good" became "fair" to "excellent".

\section{CONCLUSION}

Sound pressure level measured in NICU has a value of $54.3 \mathrm{dBA}-62.5 \mathrm{dBA}$ and it exceeded the standards for acoustic room in hospital for World Health Organization (WHO) and National Standardization Agency of Indonesia (SNI). Based on the perspective of the nurses as respondents in this research, most annoying sounds came from medical instrumentation and medical officer conversation. Scale performance of acoustic room according to respondent were 4.2 for noisy scale and 5.2 for comfort scale, and it can be concluded that the acoustic room condition were noisy and uncomfortable for the occupants. Improvement design was done by adding curtain absorber alongside the incubator, using ceiling absorber in nurse station, and glass partitions between the babies area and nurse station. With this improvement, the sound pressure level decreased with average value $8.9 \mathrm{dBA}$ for sound source alarm ventilator and $8.2 \mathrm{dBA}$ for sound source medical officer conversations. The speech transmission index increased from "bad" to "good" range became "fair" to "excellent" range.

\section{Acknowledgment}

This research was funded by Riset Unggulan Perguruan Tinggi Indonesia from The Ministry of Research and Higher Education Republic of Indonesia.

\section{REFERENCES}

"Absorption Coefficients $\alpha$ of Building Materials and Finishes". [Online]. Available. http://www. sengpielaudio.com/calculator-RT60Coeff.htm. [Accessed: 30 - June -2016].

"Absorption Coefficients". [Online]. Available. http://www.acoustic.ua/st/web_absorption_data_ eng.pdf. [Accessed: 30 - June - 2016].

Indonesian National Standard. National (2000). SNI 03-6386-2000. Jakarta: Standardization Agency of Indonesia.

International Organization for Standardization (2003). ISO 9921:2003 - Ergonomics - Assessment of Speech Communication.

International Organization for Standardization (2012). ISO 3383-3: 2012 - Acoustics -- Measurement of Room Acoustic Parameters; Part 3: Open Plan Offices.

M.Vorlander. (2007). CERN Document Server. [Online]. Available. https://cds.cern.ch/record/ 1251519/files/978-3-540-48830-9_BookBack Matter.pdf [Accessed: 25 - June - 2016].

"NICU/PICU". [Online]. Available. http://bunda.co. id/rsiabundajakarta/id_ID/facilities-and-services/support-facilities/nicupicu/. [Accessed: 30 - June - 2016]

Ryherd, E. E., Waye, K. P. \& Ljungkvist, L. (2007). Characterizing Noise and Perceived Work Environment in A Neurological Intensive Care Unit. J. Acoust. Soc. Am., 123(2), p.1.

WHO, Guidelines Values for Community Noise. [Online]. Available. http://www.who.int/docstore/peh/noise/Comnoise-4.pdf [Accessed: 21 Maret 2016]. 